\title{
Lisina digestível para suínos machos castrados de alta deposição de carne submetidos a estresse por calor dos 30 aos $60 \mathrm{~kg}^{1}$
}

\author{
Rubens Mauro Batista ${ }^{2}$, Rita Flávia Miranda de Oliveira ${ }^{3}$, Juarez Lopes Donzele ${ }^{3}$, Will \\ Pereira de Oliveira ${ }^{2}$, Anderson Lazarini Lima ${ }^{2}$, Márvio Lobão Teixeira de Abreu ${ }^{4}$
}

\author{
1 Projeto financiado pela AJINOMOTO. \\ 2 Mestrando DZO,UFV. \\ ${ }^{3}$ DZO UFV \\ ${ }^{4}$ DZO,UFPI.
}

RESUMO - Este estudo foi realizado para avaliar níveis de lisina digestível para suínos dos 30 aos 60 kg mantidos sob estresse por calor. Utilizaram-se 70 suínos machos castrados mantidos em ambiente a $30^{\circ} \mathrm{C}$ e outros 70 em ambiente a $34^{\circ} \mathrm{C}$, distribuídos em delineamento de blocos ao acaso, com cinco tratamentos $(0,83 ; 0,93 ; 1,03 ; 1,13$ e $1,23 \%$ de lisina digestível), sete repetições e dois animais por unidade experimental. $\mathrm{O}$ ganho de peso diário dos animais mantidos a $30^{\circ} \mathrm{C}$ aumentou até o nível de $1,04 \%$ de lisina digestível, mas a $34^{\circ} \mathrm{C}$ não variou. $\mathrm{O}$ consumo de ração diário dos animais a 30 e a $34^{\circ} \mathrm{C}$ não variou com os níveis de lisina. O consumo de lisina diário dos animais, em ambos os ambientes, aumentou de acordo com o nível de lisina da ração. A $30^{\circ} \mathrm{C}$, a conversão alimentar melhorou até o nível de $1,07 \%$ de lisina, enquanto a $34^{\circ} \mathrm{C}$ não variou entre os níveis de lisina. Independentemente da temperatura, a eficiência de utilização de lisina reduziu conforme aumentaram os níveis de lisina e foi 4,4\% pior no ambiente com temperatura mais elevada. A deposição de proteína na carcaça dos animais no ambiente a $30^{\circ} \mathrm{C}$ aumentou até o nível de $1,05 \%$ de lisina, mas não variou no ambiente a $34^{\circ} \mathrm{C}$. A $30^{\circ} \mathrm{C}$, a deposição de gordura reduziu até o nível de $1,08 \%$ de lisina, enquanto a $34^{\circ} \mathrm{C}$, aumentou até o nível de $1,08 \%$ e foi, em média, $25,6 \%$ menor que a $30^{\circ} \mathrm{C}$. Os níveis de triiodotironina e tiroxina foram 35 e $30 \%$, respectivamente, menores nos animais mantidos em ambiente a $34^{\circ} \mathrm{C}$, em que a frequência respiratória e temperatura retal também foram mais altas que as observadas nos animais mantidos a $30^{\circ} \mathrm{C}$. Os níveis de 1,04 e $0,83 \%$ de lisina digestível proporcionam maior ganho de peso e deposição de proteína em suínos mantidos, respectivamente, em ambientes a 30 e $34^{\circ} \mathrm{C}$.

Palavras-chave: ambiente, aminoácido, desempenho, hormônios da tireóide, temperatura

\section{Digestible lysine levels for high lean deposition barrows from 30 to $60 \mathrm{~kg}$ kept under heat stress}

\footnotetext{
ABSTRACT - This study was conducted to evaluate levels of digestible lysine for pigs at 30 to $60 \mathrm{~kg}$ kept under heat stress. It was used 70 castrated animals kept in environment at $30^{\circ} \mathrm{C}$ and others $70 \mathrm{kept}$ at $34^{\circ} \mathrm{C}$, distributed in a randomized block design, with five treatments $(0.83,0.93,1.03,1.13$ and $1.23 \%$ digestible lysine), and seven repetitions with two animals per experimental unit. The daily weight gain of the animals kept at $30^{\circ} \mathrm{C}$ increased up to $1.04 \%$ of digestible lysine, whereas it did not change at $34^{\circ} \mathrm{C}$. Feed daily intake of animals at $30^{\circ} \mathrm{C}$ and $34^{\circ} \mathrm{C}$ did not change with levels of lysine. Daily lysine intake of animals, in both environments, increased according to the level of lysine in the diet. At $30^{\circ} \mathrm{C}$, feed conversion improved up to the level of $1.07 \%$ lysine, whereas at $34^{\circ} \mathrm{C}$, it did not vary among lysine levels. Regardless of the temperature, use efficiency of lysine decreased as levels of lysine increased and it was $4.4 \%$ worse in the environment with higher temperature. Protein deposition in carcass in the $30^{\circ} \mathrm{C}$ environment increased up to the level of $1.05 \%$ lysine, but it did not change at $34^{\circ} \mathrm{C}$. At $30^{\circ} \mathrm{C}$, fat deposition decreased down to $1.08 \%$ lysine, whereas in the $34^{\circ} \mathrm{C}$ environment, it increased up to $1.08 \%$, and it was on average $25.6 \%$ lower than at $30^{\circ} \mathrm{C}$. Levels of triiodothyronine and thyroxine were 35 and $30 \%$, respectively, which was lower in animals kept in the $34^{\circ} \mathrm{C}$ environment, where respiratory rate and rectal temperature were higher than those observed in animals kept in the environment at $30^{\circ} \mathrm{C}$. The levels of 1.04 and $0.83 \%$ of digestible lysine provide greater weight gain and protein deposition in pigs kept in environments at $30^{\circ} \mathrm{C}$ and $34^{\circ} \mathrm{C}$, respectively.
}

Key Words: amino acid, environment, performance, temperature, thyroidal hormones 


\section{Introdução}

A busca pela melhoria na qualidade da carcaça tem levado à seleção e produção de suínos com alto potencial genético para desempenho, eficiência alimentar e crescimento de tecido muscular. A introdução desses novos genótipos aumenta a preocupação com o ambiente térmico onde os suínos vivem, pois essas linhagens modernas podem ser mais sensíveis, uma vez que apresentam maior deposição de carne (White et al., 2008), que tem sido associada à maior produção de calor metabólico.

A taxa de crescimento de tecido muscular de um suíno é influenciada, entre outros fatores, pelo consumo de ração. A deposição de proteína aumenta de acordo com o consumo de energia até atingir uma estabilidade (Schinckel, 2001), ou seja, o máximo permitido pelo potencial genético. Quando o limite genético de deposição de músculos é atingido, o consumo em excesso de energia passa a promover deposição de gordura na carcaça (Bellaver \& Viola, 1997).

A deposição de tecido muscular com o consumo de energia só é eficientemente obtida se o aporte de aminoácidos, principalmente lisina, for suficiente para permitir a expressão genética do animal (Main et al., 2008). Dessa forma, suínos com altas taxas de deposição de proteína têm exigências mais altas de aminoácidos para expressar seu potencial genético de crescimento e eficiência para deposição de tecido muscular.

A análise do ambiente térmico no qual os suínos estão inseridos, além dos fatores como genótipo, sexo e fase de crescimento, deve ser considerada na determinação das exigências nutricionais e na formulação de rações (Saraiva et al., 2007), uma vez que, em temperaturas fora da faixa de termoneutralidade, o consumo de ração é alterado.

A lisina é o primeiro aminoácido limitante em rações à base de milho e farelo de soja para suínos em crescimento (Nunes et al., 2008). O nível desse aminoácido na ração pode influenciar significativamente o desempenho e a composição de carcaça dos animais. Assim, a determinação da exigência desse aminoácido é necessária para definir os padrões de alimentação dos animais. Além disso, considerando que no Brasil a maioria das granjas de suínos está sujeita a variações de temperaturas e à predominância de dias quentes, este estudo foi realizado para avaliar níveis de lisina digestível para suínos machos castrados de alto potencial genético para deposição de carne na carcaça na fase dos 30 aos $60 \mathrm{~kg}$ mantidos em ambiente de calor.

\section{Material e Métodos}

Foram conduzidos dois experimentos no Setor de Suinocultura do Departamento de Zootecnia do Centro de
Ciências Agrárias da Universidade Federal de Viçosa, em Viçosa, Minas Gerais, utilizando-se 140 suínos machos castrados de alto potencial genético para deposição de carne, em fase de crescimento (30 a $60 \mathrm{~kg}$ de peso): 70 animais em ambiente com temperatura de $30^{\circ} \mathrm{C}$ e outros 70 animais em ambiente com temperatura de $34^{\circ} \mathrm{C}$. Em ambos os experimentos, os animais foram distribuídos em delineamento experimental de blocos ao acaso, com cinco níveis de lisina digestível $(0,83 ; 0,93 ; 1,03 ; 1,13$ ou $1,23 \%)$, sete repetições e dois animais por unidade experimental. Os animais foram alojados em gaiolas metálicas, com piso ripado, providas de comedouro semi-automático e bebedouro tipo chupeta, e mantidos em sala climatizada (temperatura controlada) em ambientes de calor moderado $\left(30^{\circ} \mathrm{C}\right)$ e de calor intenso $\left(34^{\circ} \mathrm{C}\right)$ para a respectiva fase.

Em ambos os experimentos, para garantir o ambiente térmico, as temperaturas foram monitoradas diariamente, três vezes ao dia (às 7, 12 e 17 h), por meio de termômetros de máxima e mínima, de bulbo seco e bulbo úmido e de globo negro. Os dados de temperatura foram posteriormente convertidos no índice de temperatura de globo e umidade (ITGU), conforme descrito por Buffington et al. (1981).

As rações experimentais, isoenergéticas e isoproteicas, foram formuladas à base de milho e farelo de soja (Tabela 1) para atender às exigências nutricionais dos animais, com exceção das de lisina digestível, de acordo com descrições de Rostagno et al. (2005). Os níveis de lisina digestível das rações foram obtidos a partir da inclusão de L-lisina $\mathrm{HCl} \mathrm{em}$ substituição ao amido. Em todos os níveis de lisina avaliados, foi checada a relação aminoacídica entre lisina digestível e os demais aminoácidos essenciais digestíveis, os quais foram mantidos em níveis $2 \%$ acima do recomendado por Rostagno et al. (2005), a fim de assegurar que nenhum outro aminoácido ficasse limitante nas rações.

As rações experimentais e a água foram fornecidas à vontade. Os animais foram pesados individualmente no início e ao final dos experimentos, para determinação do ganho de peso. O consumo de ração foi determinado pela diferença entre a quantidade de ração oferecida aos animais e as sobras dos comedouros, mais o desperdício, no período total.

Em ambos os experimentos, nos animais alimentados com a ração contendo $1,03 \%$ de lisina digestível, a temperatura retal foi monitorada por meio de termômetro clínico veterinário, introduzido no reto durante um minuto, às $10 \mathrm{~h}$, a cada 15 dias. Nesses mesmos dias e horários, também foi feito o registro da freqüência respiratória, por meio da contagem dos movimentos do flanco do animal durante 15 segundos, corrigindo-se os valores para 1 minuto. 
Tabela 1 - Composição das rações experimentais

\begin{tabular}{|c|c|c|c|c|c|}
\hline \multirow[t]{2}{*}{ Ingrediente $(\%)$} & \multicolumn{5}{|c|}{ Nível de lisina digestível (\%) } \\
\hline & 0,83 & 0,93 & 1,03 & 1,13 & 1,23 \\
\hline Milho & 66,434 & 66,434 & 66,434 & 66,434 & 66,434 \\
\hline Farelo de soja $45 \%$ & 27,743 & 27,743 & 27,743 & 27,743 & 27,743 \\
\hline Óleo de soja & 0,790 & 0,790 & 0,790 & 0,790 & 0,790 \\
\hline Fosfato bicálcico & 1,240 & 1,240 & 1,240 & 1,240 & 1,240 \\
\hline Calcário & 0,627 & 0,627 & 0,627 & 0,627 & 0,627 \\
\hline Sal comum & 0,406 & 0,406 & 0,406 & 0,406 & 0,406 \\
\hline Mistura mineral ${ }^{1}$ & 0,200 & 0,200 & 0,200 & 0,200 & 0,200 \\
\hline Mistura vitamínica ${ }^{2}$ & 0,200 & 0,200 & 0,200 & 0,200 & 0,200 \\
\hline Sulfato de colistina & 0,050 & 0,050 & 0,050 & 0,050 & 0,050 \\
\hline Butil-hidroxi-tolueno & 0,010 & 0,010 & 0,010 & 0,010 & 0,010 \\
\hline Amido & 2,300 & 2,108 & 1,828 & 1,504 & 1,142 \\
\hline L-lisina $\mathrm{HCl}$ & - & 0,129 & 0,258 & 0,387 & 0,517 \\
\hline DL-metionina & - & 0,042 & 0,105 & 0,168 & 0,232 \\
\hline L-treonina & - & 0,021 & 0,095 & 0,169 & 0,243 \\
\hline L-triptofano & - & - & 0,014 & 0,036 & 0,057 \\
\hline L-valina & - & - & - & 0,036 & 0,109 \\
\hline \multicolumn{6}{|l|}{ Composição calculada } \\
\hline Proteína bruta $(\%)$ & 18,061 & 18,061 & 18,061 & 18,061 & 18,061 \\
\hline Energia metabolizável (kcal/kg) & 3.234 & 3.234 & 3.234 & 3.234 & 3.234 \\
\hline Lisina total $(\%)$ & 0,928 & 1,029 & 1,130 & 1,231 & 1,333 \\
\hline Lisina digestível (\%) & 0,828 & 0,928 & 1,028 & 1,128 & 1,228 \\
\hline Metionina + cistina digestível $(\%)$ & 0,534 & 0,576 & 0,637 & 0,699 & 0,762 \\
\hline Treonina digestível (\%) & 0,603 & 0,622 & 0,689 & 0,756 & 0,823 \\
\hline Triptofano digestível (\%) & 0,192 & 0,192 & 0,205 & 0,226 & 0,246 \\
\hline Valina digestível (\%) & 0,765 & 0,765 & 0,765 & 0,800 & 0,872 \\
\hline Cálcio $(\%)$ & 0,631 & 0,631 & 0,631 & 0,631 & 0,631 \\
\hline Fósforo disponível (\%) & 0,332 & 0,332 & 0,332 & 0,332 & 0,332 \\
\hline Sódio $(\%)$ & 0,180 & 0,180 & 0,180 & 0,180 & 0,180 \\
\hline
\end{tabular}

1 Composição por quilograma do produto: ferro, $100 \mathrm{~g}$; cobre, $10 \mathrm{~g}$; cobalto, $1 \mathrm{~g}$; manganês, $40 \mathrm{~g}$; zinco, $100 \mathrm{~g}$; iodo, $1,5 \mathrm{~g}$ e excipiente q.s.p., 747,5 g.

${ }^{2}$ Composição por quilograma do produto: vitamina A, 6.000.000 UI; vitamina $\mathrm{D}_{3}, 1.500 .000$ UI; vitamina E, 15.000 .000 UI; vitamina $\mathrm{B}_{1}, 1,35$ g; vitamina $\mathrm{B}_{2}, 4 \mathrm{~g}$; vitamina

$\mathrm{B}_{6}, 2 \mathrm{~g}$; ácido pantotênico, $9,35 \mathrm{~g}$; vitamina $\mathrm{K}_{3}, 1,5 \mathrm{~g}$; ácido nicotínico, 20,0g; vitamina B12, 20,0g; ácido fólico, $0,6 \mathrm{~g}$; biotina, $0,08 \mathrm{~g}$; selênio, $0,3 \mathrm{~g}$ e excipiente q. $\mathrm{s}$. p., $1.000 \mathrm{~g}$.

O período experimental foi de 32 dias no ambiente de $30^{\circ} \mathrm{C}$ e 37 dias no de $34^{\circ} \mathrm{C}$. No final do período experimental, os animais com peso de $60,0 \pm 3,24 \mathrm{~kg}$ e $59,3 \pm 4,00 \mathrm{~kg}$, nos ambientes de $30 \mathrm{e} 34^{\circ} \mathrm{C}$, respectivamente, foram submetidos a jejum alimentar de 24 horas. Após as primeiras três horas de jejum, foi coletado sangue dos animais alimentados com a ração com 1,03\% de lisina digestível, por punção do Sinus orbital, para dosagem de triiodotironina (T3) e tiroxina (T4), realizada por meio de kits de determinação imunoenzimática.

Após o período de jejum, um animal de cada repetição, com peso mais próximo de $60 \mathrm{~kg}$, foi abatido por sangramento, depilado e eviscerado. As carcaças inteiras, incluindo pés e cabeça, foram pesadas. Posteriormente, as meias-carcaças foram trituradas por 15 minutos em cutter comercial de $30 \mathrm{HP}$ e 1.775 revoluções por minuto. Após homogeneização, foram retiradas amostras, conforme processo descrito por Donzele et al. (1992), que foram conservadas a $-12^{\circ} \mathrm{C}$ para posterior determinação das composições de proteína e gordura das carcaças.

Um grupo adicional de cinco animais, de mesmo sexo e genética, com peso médio de $30 \mathrm{~kg}$, foi abatido para determinação da composição da carcaça (proteína e gordura) no início do período experimental. Em ambos os experimentos, as deposições de proteína e gordura nas carcaças dos animais foram calculadas comparando-se as composições das carcaças dos animais no início e no fim de cada período experimental.

As análises bromatologicas dos ingredientes e das rações foram realizadas no Laboratório de Nutrição Animal do Departamento de Zootecnia da UFV, de acordo com metodologia descrita por Silva (1990).

Nos dois experimentos, as análises estatísticas dos dados de desempenho (ganho de peso, consumo de ração e conversão alimentar), das deposições de proteína e gordura nas carcaças e dos parâmetros fisiológicos e hormonais foram realizadas utilizando-se o programa computacional SAEG (Sistemas de Análises Estatísticas e Genéticas), desenvolvido na Universidade Federal de Viçosa (UFV).

A estimativa da exigência de lisina em cada ambiente térmico foi feita com base nos resultados de desempenho e deposições de proteína e gordura na carcaça utilizando-se os modelos de regressão linear. 


\section{Resultados e Discussão}

Considerando que a zona de termoneutralidade para suínos na fase de crescimento está entre 18 e $23^{\circ} \mathrm{C}$ (Perdomo, 1994) e que, segundo Saraiva et al. (2007) e Orlando et al. (2001), os ITGU, respectivos, de 72,4 e de 79,7, caracterizam como termoneutro e de estresse por calor o ambiente de suínos dos 30 aos $60 \mathrm{~kg}$, pode-se deduzir, com base nas temperaturas registradas no interior dos galpões $(30,0 \mathrm{e}$ $\left.34,2^{\circ} \mathrm{C}\right)$ e nos respectivos valores de ITGU $(80,9$ e 86,8$)$ observados neste estudo (Tabela 2 ), que os animais foram submetidos a um ambiente termicamente estressante.

Os níveis de lisina digestível influenciaram $(\mathrm{P}<0,07)$ o ganho de peso diário (GPD) dos animais mantidos em ambiente com calor moderado $\left(30^{\circ} \mathrm{C}\right)$, que aumentou de forma quadrática até o nível estimado de 1,04\% (Tabela 3; Figura 1). De forma similar, Warnants et al. (2003) avaliando níveis de lisina digestível para suínos machos castrados dos 30 aos $49 \mathrm{~kg}$ obtiveram melhor resposta de GPD no nível de $1,09 \%$.

Tabela 2 - Temperaturas dos termômetros de bulbo seco, umidade relativa e índice de temperatura de globo e umidade (ITGU) por experimento

\begin{tabular}{lccc}
\hline & \multicolumn{3}{c}{ Parâmetros ambientais } \\
\cline { 2 - 4 } & $\begin{array}{c}\text { Temperatura de } \\
\text { bulbo seco }\left({ }^{\circ} \mathrm{C}\right)\end{array}$ & $\begin{array}{c}\text { Umidade } \\
\text { relativa }(\%)\end{array}$ & ITGU \\
\hline Ambiente $30^{\circ} \mathrm{C}$ & $30,0 \pm 0,86$ & $80 \pm 7,6$ & $80,9 \pm 1,3$ \\
Ambiente $34^{\circ} \mathrm{C}$ & $34,2 \pm 0,86$ & $77 \pm 5,5$ & $86,8 \pm 1,2$ \\
\hline
\end{tabular}

Por outro lado, o ganho de peso dos animais mantidos em ambiente com temperatura de $34^{\circ} \mathrm{C}$ não variou $(\mathrm{P}>0,10)$ com o aumento dos níveis de lisina digestível. O ganho de peso diário dos animais mantidos no ambiente com temperatura de $34^{\circ} \mathrm{C}$ foi em média $13,4 \%$ menor $(\mathrm{P}<0,01)$ que o daqueles mantidos no ambiente de $30^{\circ} \mathrm{C}$. De forma semelhante, Manno et al. (2005) e Saraiva et al. (2006), comparando o desempenho de suínos machos de 15 a $30 \mathrm{~kg}$ mantidos em ambiente de 34 e $30^{\circ} \mathrm{C}$, respectivamente, ao desempenho de animais mantidos em ambiente termoneutro, constataram redução de 22 e $8 \%$ no ganho de peso diário. A redução do ganho de peso verificada neste estudo confirma a hipótese de que animais mantidos em ambiente

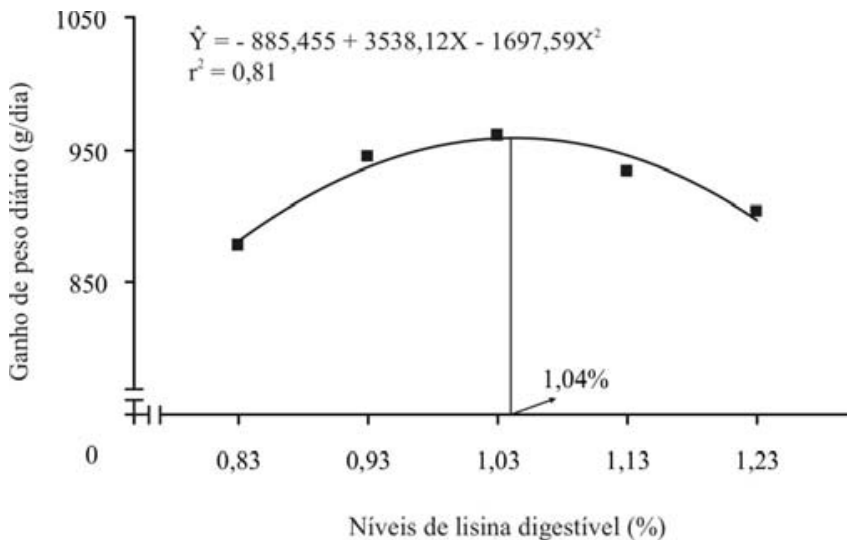

Figura 1 - Ganho de peso diário de suínos dos 30 aos $60 \mathrm{~kg}$ mantidos em ambiente de $30^{\circ} \mathrm{C}$.

Tabela 3 - Desempenho de suínos dos 30 aos $60 \mathrm{~kg}$ mantidos em ambiente de estresse por calor

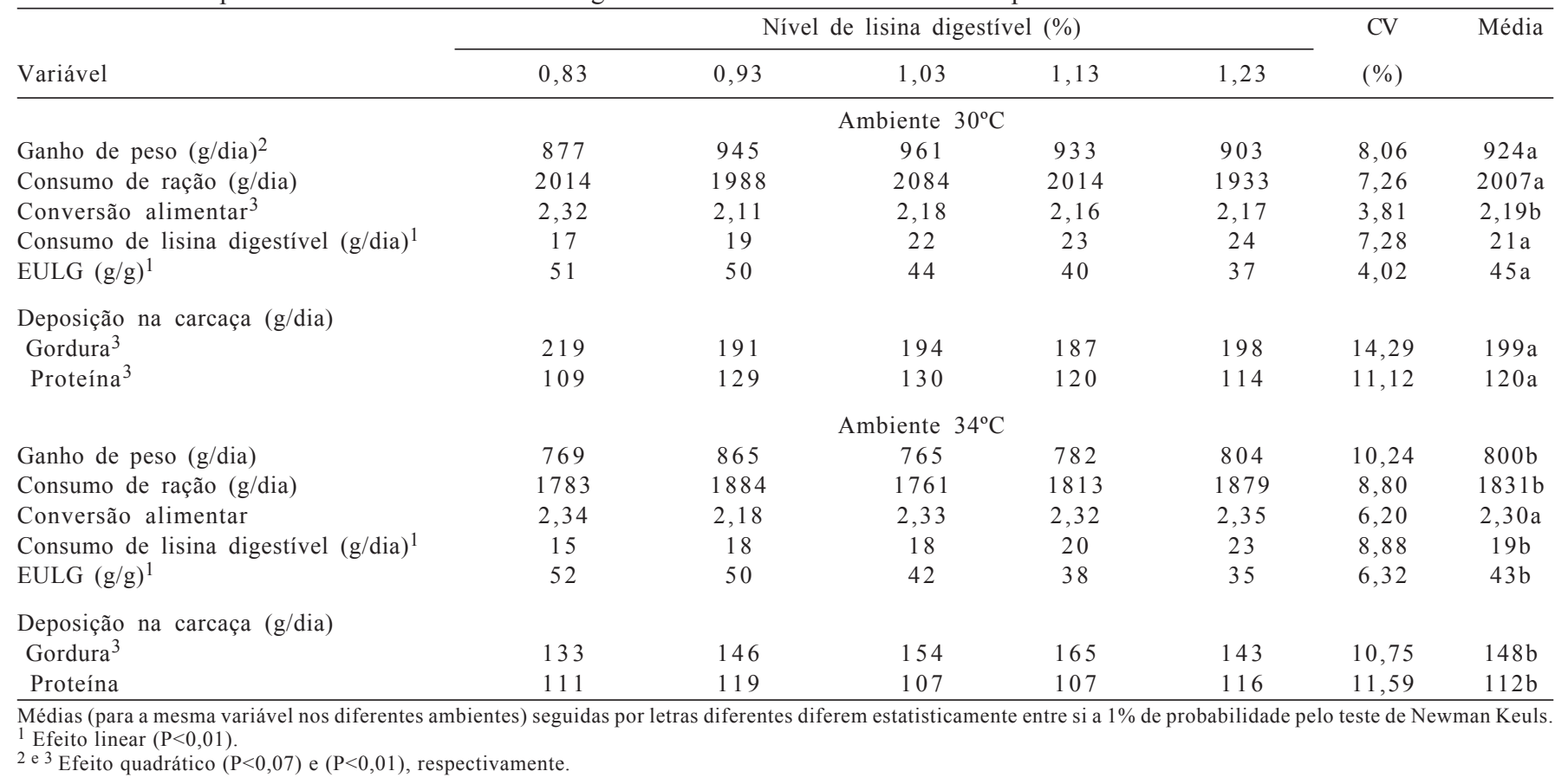


com temperatura acima da faixa de termoneutralidade utilizam ajustes comportamentais e fisiológicos para favorecer o balanço de calor, o que compromete o seu desempenho, o que está coerente com os relatos de Tavares et al. (2000), Collin et al. (2001b), Orlando et al. (2001), Kerr et al. (2003) e Kiefer et al. (2005). No entanto, de acordo com os resultados de ganho de peso obtidos, o efeito negativo dos ajustes metabólicos sobre o desempenho dos animais expostos a alta temperatura varia em função da intensidade do estresse.

O consumo de ração diário (CRD), independentemente da temperatura em que os animais foram mantidos, não foi influenciado $(\mathrm{P}>0,10)$ pelos níveis de lisina digestível das rações. De forma similar, Cline et al. (2000) e Fontes et al. (2000) também não observaram efeito dos níveis de lisina sobre o consumo de ração em suínos em crescimento. Entretanto, Chen et al. (1999), King et al. (2000) e Fontes et al. (2005) constataram variação significativa na ingestão voluntária de alimento dos suínos em crescimento em razão do aumento do nível de lisina da ração.

A divergência de resultados entre os trabalhos pode estar relacionada a fatores como: composição da ração, níveis de lisina digestível avaliados e temperatura ambiente.

$\mathrm{Na}$ avaliação do ambiente térmico, o consumo de ração dos animais mantidos a $34^{\circ} \mathrm{C}$, foi em média $9,0 \%$ menor $(\mathrm{P}<0,01)$ que o daqueles mantidos a $30^{\circ} \mathrm{C}$. Efeito negativo da alta temperatura sobre o consumo diário de ração de suínos em crescimento foi verificado também por Tavares et al. (2000), Collin et al. (2001a), Le Bellego et al. (2002a) e Manno et al. (2005).

A redução no consumo diário de ração observada neste estudo entre os animais mantidos a 34 e $30^{\circ} \mathrm{C}$, correspondeu a $46 \mathrm{~g} /{ }^{\circ} \mathrm{C}$. Este valor é semelhante ao de $45 \mathrm{~g} / \mathrm{dia} /{ }^{\circ} \mathrm{C}$, observado por Le Bellego et al. (2002b), em estudo com suínos em crescimento.

Os efeitos negativos de altas temperaturas sobre a ingestão de alimentos permitem inferir que a redução no consumo é um dos principais ajustes metabólicos do animal para reduzir a produção de calor corporal. Esta hipótese está coerente com o relato de Santomá \& Pontes (2004) de que o padrão de redução do consumo de ração aumenta de forma direta com a intensidade do estresse por calor, embora em uma relação não-linear. No entanto, de acordo com Collin et al. (2001b), isoladamente, a redução do consumo diário de ração ocasionada pela alta temperatura não explicaria o menor ganho de peso pelos animais.

Observou-se efeito $(\mathrm{P}<0,01)$ dos níveis de lisina sobre o consumo diário de lisina dos animais mantidos a $30 \mathrm{e}$ $34^{\circ} \mathrm{C}$, que aumentou de forma linear, respectivamente, segundo as equações: $\hat{Y}=1,84732+18,2640 X\left(r^{2}=0,98\right)$ e $\hat{Y}=-1,83325+19,9960 X\left(r^{2}=0,98\right)$. Como o consumo de ração não variou com o nível de lisina em ambos os ambientes avaliados, o aumento no consumo diário de lisina esteve diretamente relacionado à concentração desse aminoácido na ração. No ambiente de $34^{\circ} \mathrm{C}$, o consumo diário de lisina foi em média $9,5 \%$ menor $(\mathrm{P}<0,01)$ que o observado no ambiente com temperatura mais baixa $\left(30^{\circ} \mathrm{C}\right)$, o que reflete a variação do consumo de ração entre as duas temperaturas ambientes.

O efeito dos níveis de lisina sobre a conversão alimentar variou de acordo com a temperatura ambiente. Enquanto no ambiente de $34^{\circ} \mathrm{C}$ a conversão alimentar dos animais não foi influenciada $(\mathrm{P}>0,10)$ pelos níveis de lisina, no ambiente de $30^{\circ} \mathrm{C}$, a conversão melhorou $(\mathrm{P}<0,01)$ de forma quadrática até o nível estimado de $1,07 \%$ (Figura 2). Efeito similar do nível de lisina digestível sobre a conversão alimentar de suínos em crescimento também foi observado por Abreu et al. (2007), que obtiveram a melhor resposta no nível estimado $1,10 \%$.

Os valores de conversão alimentar obtidos nos animais mantidos a $34^{\circ} \mathrm{C}$ foram em média $5,0 \%$ maiores $(\mathrm{P}<0,01)$ que os encontrados nos animais mantidos a $30^{\circ} \mathrm{C}(2,30 \times 2,19)$.

A piora na conversão alimentar dos animais mantidos a $34^{\circ} \mathrm{C}$ foi ocasionada pela redução mais acentuada do ganho de peso $(13,4 \%)$ em relação à redução no consumo diário de ração $(9,0 \%)$. Desta forma, os piores resultados de desempenho nos animais mantidos no ambiente a $34^{\circ} \mathrm{C}$ indicam que o aumento na temperatura ambiente de 30 para $34^{\circ} \mathrm{C}$ promoveu ajustes metabólicos e endócrinos (Le Dividich et al., 1992; Brown-Brandl et al., 2001), que provavelmente comprometeram mais acentuadamente a capacidade de crescimento dos animais.

Independentemente da temperatura ambiental, os níveis de lisina influenciaram $(\mathrm{P}<0,01)$ a eficiência de utilização de lisina para ganho de peso, que reduziu de forma linear segundo as equações: $\hat{Y}=85,3624-38,7633 \mathrm{X}\left(\mathrm{r}^{2}=0,97\right) \mathrm{e}$

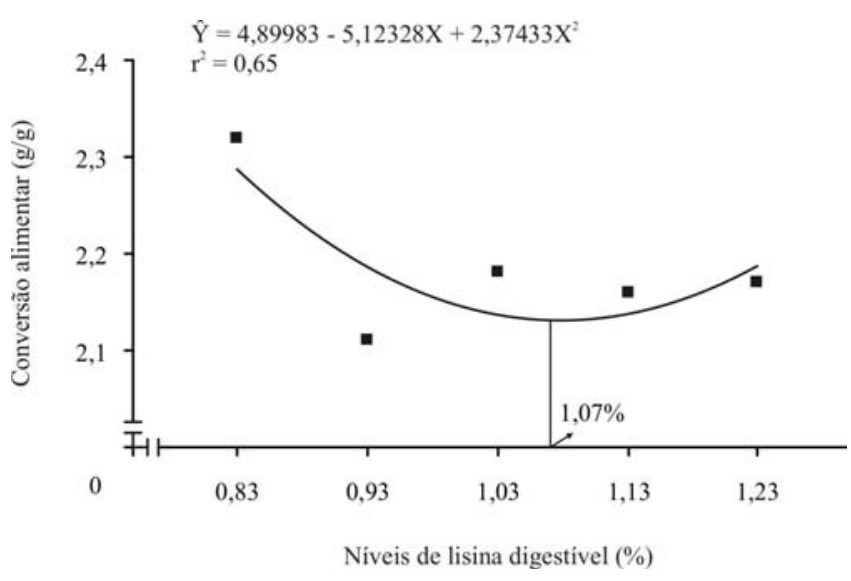

Figura 2 - Conversão alimentar de suínos dos 30 aos $60 \mathrm{~kg}$ mantidos em ambiente de $30^{\circ} \mathrm{C}$. 
$\hat{\mathrm{Y}}=89,3179-44,7848 \mathrm{X}\left(\mathrm{r}^{2}=0,98\right)$, respectivamente, nos ambientes de 30 e $34^{\circ} \mathrm{C}$. Em experimento realizado por Lee et al. (1996) com suínos em crescimento, a eficiência de utilização de lisina para ganho de peso reduziu quando a porcentagem de lisina em relação à de $\mathrm{PB}$ da ração aumentou de 5,2 para $6,7 \%$. Considerando os resultados obtidos por esses autores, pode-se deduzir que, entre outros fatores, a elevação da relação lisina:proteína de 4,6 até $6,8 \%$ verificada neste trabalho pode ter contribuído para a redução na eficiência de utilização de lisina para ganho de peso dos suínos em ambos os ambientes avaliados.

Os animais mantidos no ambiente com temperatura mais elevada $\left(34^{\circ} \mathrm{C}\right)$ apresentaram piora $(\mathrm{P}<0,01)$ de $4,5 \%$ na eficiência de utilização de lisina. Redução na eficiência de utilização da lisina para ganho de peso com o aumento da temperatura ambiente também foi observada por Manno et al. (2005) em suínos em crescimento alimentados à vontade.

Considerando o relato de Kerr et al. (2003), que a intensidade de redução no consumo diário de ração está inversamente relacionada à eficiência de utilização da lisina, pode-se deduzir que o menor valor de eficiência de utilização da lisina verificado nos animais mantidos em ambiente com temperatura de $34^{\circ} \mathrm{C}$ pode estar relacionado ao menor consumo diário de ração $(9,0 \%)$ desses animais.

$\mathrm{O}$ nível de lisina digestível influenciou $(\mathrm{P}<0,01)$ a deposição de proteína na carcaça dos animais mantidos no ambiente com temperatura de $30^{\circ} \mathrm{C}$, que aumentou de forma quadrática até o nível estimado de $1,05 \%$, correspondente a consumo diário estimado de $21 \mathrm{~g}$ de lisina digestível (Figura 3). Entretanto, nos animais mantidos em ambiente de $34^{\circ} \mathrm{C}$, a deposição de proteína não variou $(\mathrm{P}>0,10)$ entre os níveis de lisina da ração.

A diferença de resposta aos níveis de lisina digestível entre os animais mantidos nos ambientes de 30 e $34^{\circ} \mathrm{C}$ pode

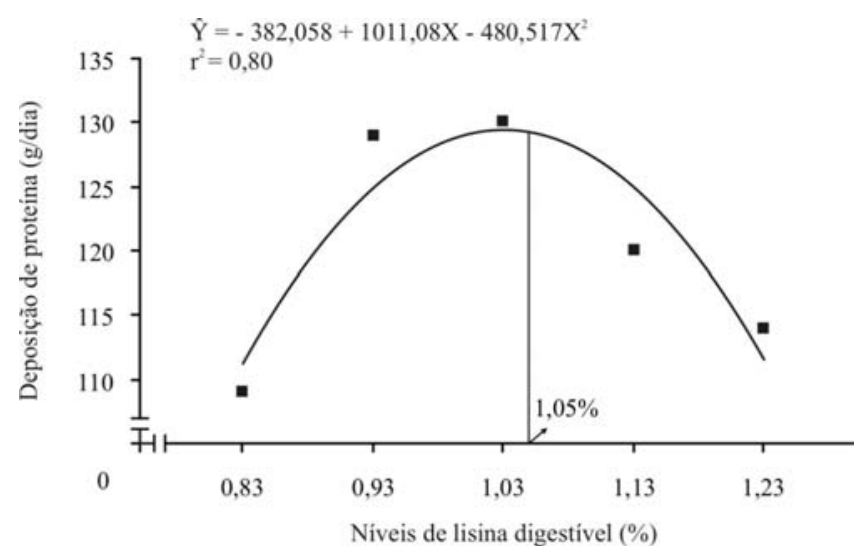

Figura 3 - Deposição de proteína em suínos dos 30 aos $60 \mathrm{~kg}$ mantidos em ambiente de $30^{\circ} \mathrm{C}$ ser um indicativo de que a capacidade de retenção de nitrogênio dos animais mantidos no ambiente com temperatura mais elevada $\left(34^{\circ} \mathrm{C}\right)$ foi mais comprometida, diminuindo a exigência de lisina. Confirmando esta hipótese, a deposição de proteína dos animais mantidos a $34^{\circ} \mathrm{C}$ foi em média $6,7 \%$ menor $(\mathrm{P}<0,01)$ que a daqueles mantidos em ambiente com temperatura mais baixa $\left(30^{\circ} \mathrm{C}\right)$. De acordo com Kloareg et al. (2005), a alta temperatura ambiente limita a deposição de proteína na carcaça. De forma coerente com esta proposição Le Bellego et al. (2002b), em estudos conduzidos com suínos em crescimento, verificaram que a capacidade de deposição de proteína dos animais reduziu pelo efeito direto da alta temperatura.

A deposição de gordura na carcaça dos animais mantidos a $30^{\circ} \mathrm{C}$ variou $(\mathrm{P}<0,01)$ de forma quadrática tendo diminuído até o nível estimado de $1,08 \%$ de lisina digestível, enquanto nos mantidos a $34^{\circ} \mathrm{C}$, a deposição de gordura aumentou $(\mathrm{P}<0,01)$, de forma quadrática, até o nível de 1,08\% de lisina digestível (Figuras 4 e 5, respectivamente). Esses resultados

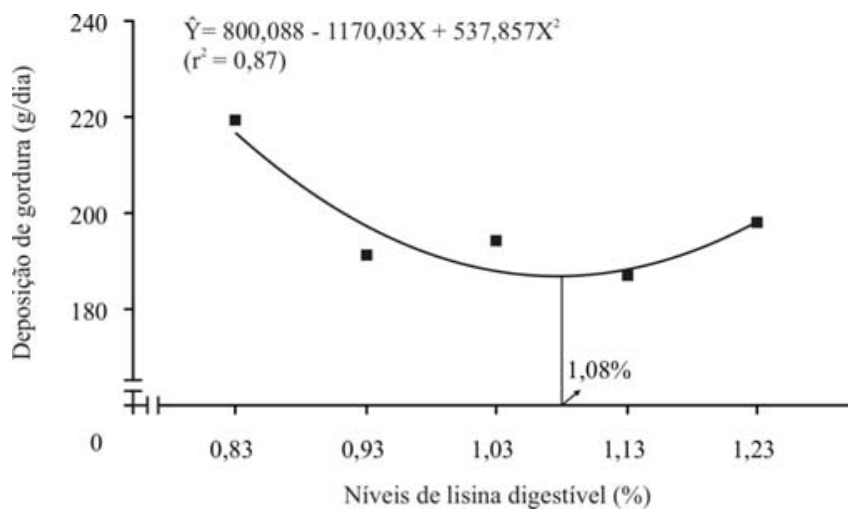

Figura 4 - Deposição de gordura em suínos dos 30 aos $60 \mathrm{~kg}$ mantidos em ambiente de $30^{\circ} \mathrm{C}$.

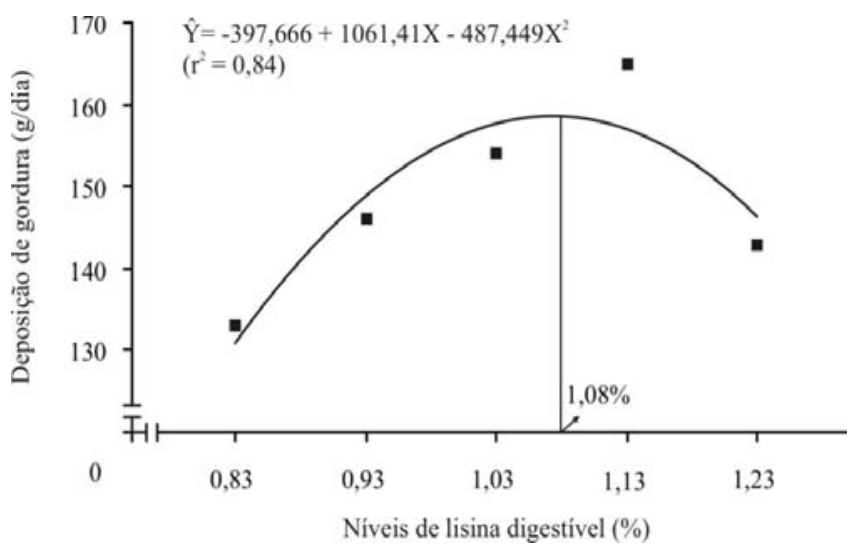

Figura 5 - Deposição de gordura em suínos dos 30 aos $60 \mathrm{~kg}$ mantidos em ambiente de $34^{\circ} \mathrm{C}$

R. Bras. Zootec., v.40, n.9, p.1925-1932, 2011 
diferem dos obtidos por Fontes et al. (2000) e Abreu et al. (2007), que não observaram efeito dos níveis de lisina sobre a deposição de gordura de suínos em crescimento. Assim, pode-se deduzir que a influência do nível de lisina sobre a deposição do tecido gorduroso dos suínos varia em função do ambiente térmico no qual o animal está exposto.

Neste trabalho, a deposição de gordura dos animais mantidos a $34^{\circ} \mathrm{C}$ foi, em média, $25,6 \%$ menor $(\mathrm{P}<0,01)$ que a daqueles mantidos a $30^{\circ} \mathrm{C}$. Esses resultados corroboram os obtidos por Collin et al. (2001b), que atribuíram a menor retenção de energia na forma de proteína e gordura nos animais, ao menor consumo de ração.

Neste estudo, a maior redução verificada na deposição de gordura $(25,6 \%)$ em relação à de proteína $(6,7 \%)$, estaria evidenciando um possível aumento na exigência de mantença dos animais mantidos a $34^{\circ} \mathrm{C}$ em relação aos mantidos a $30^{\circ} \mathrm{C}$

Os níveis plasmáticos dos hormônios triiodotironina(T3) e tiroxina (T4) dos animais foram 35 e $30 \%$, respectivamente, menores $(\mathrm{P}<0,05)$ nos animais mantidos a $34^{\circ} \mathrm{C}$ (Tabela 4$)$. Redução dos níveis dos hormônios tireoidianos em suínos submetidos ao estresse por calor também foi observada por Fialho (1994) e Oliveira \& Donzele (1999). Esse padrão de resposta é justificado pelo fato de os hormônios da tireóide estarem envolvidos na atividade metabólica dos animais e, consequentemente, na produção de calor corporal, conforme proposto por Curtis (1983) e Gass \& Kaplan (1982).

$\mathrm{Na}$ avaliação dos parâmetros fisiológicos, os animais mantidos em ambiente de $34^{\circ} \mathrm{C}$ apresentaram frequência respiratória em média $42 \%$ maior que a observada nos animais mantidos em ambiente de $30^{\circ} \mathrm{C}$. De acordo com Lopez et al. (1991), suínos sob estresse por calor aumentam a frequência respiratória como forma de intensificar a perda de calor evaporativa.

Apesar dos menores níveis plasmáticos dos hormônios tireoidianos e da maior frequência respiratória, os animais mantidos no ambiente de $34^{\circ} \mathrm{C}$ apresentaram maior $(\mathrm{P}<0,02)$ temperatura retal em comparação aos mantidos no ambiente de $30^{\circ} \mathrm{C}$. De forma semelhante, Patience et al. (2005) também observaram aumento na temperatura retal de suínos expostos à temperatura ambiente muito elevada $\left(38^{\circ} \mathrm{C}\right)$.

Considerando que a temperatura corporal de suínos é de $39,2^{\circ} \mathrm{C}$ (Bengt \& Hallgrímur, 1996), pode-se inferir que os ajustes fisiológicos e hormonais nos animais mantidos a $34^{\circ} \mathrm{C}$ não foram suficientes para manter sua homeotermia. Esse aumento da temperatura corporal dos animais mantidos a $34^{\circ} \mathrm{C}$ pode ter sido o principal fator para a redução do potencial de crescimento, o que justifica a ausência de efeito dos níveis de lisina digestível na deposição de proteína na carcaça dos animais neste ambiente.

Tabela 4 - Parâmetros fisiológicos de suínos dos 30 aos $60 \mathrm{~kg}$ mantidos em ambiente de estresse por calor

\begin{tabular}{lccc}
\hline Variável & \multicolumn{3}{c}{ Temperatura } \\
\cline { 2 - 4 } & $30^{\circ} \mathrm{C}$ & $34^{\circ} \mathrm{C}$ \\
\hline Frequência respiratória $(\mathrm{mov} / \mathrm{mim})$ & $87,57 \mathrm{~b}$ & $124,57 \mathrm{a}$ & 8,1 \\
Temperatura retal $\left({ }^{\circ} \mathrm{C}\right)$ & $39,80 \mathrm{~b}$ & $40,17 \mathrm{a}$ & 0,6 \\
Triiodotironina $(\mu \mathrm{g} / \mathrm{dL})$ & $34,35 \mathrm{a}$ & $22,31 \mathrm{~b}$ & 34,6 \\
Tiroxina $(\mathrm{ng} / \mathrm{dL})$ & $6,27 \mathrm{a}$ & $4,37 \mathrm{~b}$ & 27,3 \\
\hline
\end{tabular}

Médias seguidas pela mesma letra na mesma linha não diferem entre si pelo teste $\mathrm{F}$ a $5 \%$ de significância.

\section{Conclusões}

Em suínos machos castrados dos 30 aos $60 \mathrm{~kg}$ mantidos em ambiente a $30^{\circ} \mathrm{C}$, o nível de $1,05 \%$ de lisina digestível na ração, correspondente consumo diário de $21 \mathrm{~g}$, proporciona melhor ganho de peso diário e maior deposição de proteína na carcaça, enquanto, em ambiente com temperatura de $34^{\circ} \mathrm{C}$, o nível de $0,83 \%$ de lisina digestível na ração, correspondente a consumo diário de $15 \mathrm{~g}$, promove os melhores resultados de ganho de peso diário e deposição de proteína na carcaça.

\section{Referências}

ABREU, M.L.T.; DONZELE, J.L.; OLIVEIRA, R.F.M. et al. Níveis de lisina digestível em rações, utilizando-se o conceito de proteína ideal, para suínos machos de alto potencial genético, dos 30 aos $60 \mathrm{~kg}$. Revista Brasileira de Zootecnia, v.36, p.62-67, 2007

BELLAVER, C.; VIOLA, E.S. Qualidade de carcaça, nutrição e manejo nutricional. In: CONGRESSO BRASILEIRO DE VETERINÁRIOS ESPECIALISTAS EM SUÍNOS, 8., 1997, Foz do Iguaçu. Anais... Foz do Iguaçu: ABRAVES, 1997. p.152-158.

BENGT E.A.; HALLIGRÍMUR, J. Regulação da temperatura e fisiologia ambiental. In: SWENSON M.J.; REECE, W.O. (Eds.) Dukes fisiologia dos animais domésticos. Rio de Janeiro: Guanabara Koogan, 1996. p.805-813.

BUFFINGTON, D.E.; COLAZZO-AROCHO, A.; CANTON, G.H et al. Black globe-humidity index (BGHI) as comfort equation for dairy cows. Transaction of the American Society of Agricultural Engineering, v.24, p.711-714, 1981.

BROWN-BRANDL, T.M.; EIGENBERG, R.A.; NIENABER, J.A. et al. Thermoregulatory profile of a newer genetic line of pigs. Livestock Production Science, v.71, p.253-260, 2001.

CHEN, H.Y.; LEWIS, A.J.; MILLER, P.S. et al. The effect of excess protein on growth performance and protein metabolism of finishing barrows and gilts. Journal of Animal Science, v.77, p.3238-3247, 1999. 
CLINE, T. R.; CROMWELL, G. L.; CRENSHAW, T. D. et al. Further assessment of the dietary lysine requirement of finishing gilts. Journal of Animal Science, v.78, p.987-992, 2000.

COLLIN, A.; VAN MILGEN, J.; DUBOIS, S. et al. Effect of high temperature on feeding behaviour and heat production in grouphoused young pigs. British Journal of Nutrition, v.86, p.63-70, $2001 \mathrm{a}$.

COLLIN, A.; VAN MILGEN, J.; DUBOIS, S. et al. Effect of high temperature and feeding level on energy utilization in piglets. Journal of Animal Science, v.79, p.1849-1857, $2001 \mathrm{~b}$.

CURTIS, S.E. Environmental management in animal agriculture. 2.ed. Ames, Iowa: Iowa State Universty, 1983. 407p.

DONZELE, J.L.; COSTA P.M.A.; ROSTAGNO, H.S. et al. Efeitos de níveis de energia digestíveis na composição da carcaça de suínos de cinco a quinze quilos. Revista da Sociedade Brasileira de Zootecnia, v.21, p.1100-1106, 1992.

FONTES, D.O.; DONZELE, J.L.; OLIVEIRA, R.F.M. et al. Níveis de lisina para leitoas selecionadasgeneticamente para deposição de carne magra, dos 30 aos $60 \mathrm{~kg}$, mantendo constante a relação entre lisina e metionina + cistina, treonina, triptofano, isoleucina e valina. Revista Brasileira de Zootecnia, v.29, p.776-783, 2000

FONTES, D.O.; DONZELE, J.L.; OLIVEIRA, R.F.M. et al. Níveis de lisina para leitoas selecionadas geneticamente para deposição de carne magra na carcaça, dos 30 aos $60 \mathrm{~kg}$. Revista Brasileira de Zootecnia, v.34, p.81-89, 2005.

FIALHO, E.T. Influência da temperatura ambiental sobre a utilização da proteína e energia em suínos em crescimento e terminação. In: SIMPÓSIO LATINO-AMERICANO DE NUTRIÇÃO DE SUÍNOS, 1994, São Paulo. Anais... São Paulo: CBNA, 1994. p.63-83.

GASS, G.H.; KAPLAN, H.M. Handbook of endocrinology. Florida: CRC Press, 1982. 375p.

KERR, B.J.; YEN, J.T.; NIENABER, J.A. et al. Influence of dietary protein level, amino acid supplementation on environmental temperature on performance, body composition, organ weights and total heat production of growing pigs. Journal of Animal Science, v.81, p.1998-2007, 2003.

KIEFER, C.; FERREIRA, A.S.; OLIVEIRA, R.F.M. et al.Exigência metionina mais cistina digestíveis para suínos machos castrados mantidos em ambiente de alta temperatura dos 30 aos $60 \mathrm{~kg}$. Revista Brasileira de Zootecnia, v.34, p.104-111, 2005.

KING, R.H.; CAMPBELL, R.G.; SMITS, R.J. et al Interrelationships between dietary lysine, sex, and porcine somatotropin administration on growth performance and protein deposition in pigs between 80 and $120 \mathrm{~kg}$ live weight. Journal of Animal Science, v.78, p.2639-2651, 2000.

KLOAREG, M.; LE BELLEGO, L.; MOUROT, J. et al. Deposition of dietary fatty acids and of de novo synthesised fatty acids in growing pigs: effects of high ambient temperature and feeding restriction. British Journal of Nutrition, v.93, p.803-811, 2005.

LE BELlEGO, I.; VAN MILGEN, J.; DUBOIS, S. et al. Effect of high temperature and low-protein on the performance of growing-finishing pigs. Journal of Animal Science, v.80, p.691-701, 2002a.

LE BELLEGO, I.; VAN MILGEN, J.; NOBLET, J. Effect of high temperature on protein and lipid deposition and energy utilization in growing pigs. Animal Science, v.75, p.85-96, 2002b.

LE DIVIDICH, J.L.; HERPIN, P.; GERARERT, P.A. et al. Cold stress. In: Farm animal and the environment. Wallingford: CAB International, 1992. p.3-25.

LEE, K.U.; BOYD, D.; AUSTIC, R.E. [1996]. Metabolic efficiency of dietary protein and lysine utilization by growing pigs. Disponivel em: <http://www.nppc.org/Research/\%2796Reports/ \%2796Lee-lysineutil.html>. Acesso em: 20 nov. 2006

LOPEZ, J.; JESSE, G.W., BECKER, B.A. et al. Effect of temperature on the performance of finishing swine: effects of a hot, diurnal temperature on average daily gain, feed intake and feed efficiency. Journal of Animal Science, v.69, p.1843-1849, 1991
MAIN, R.G.; DRITZ, S.S.; TOKACH, M.D. et al. Determining an optimum lysine:calorie ratio for barrows and gilts in a commercial finishing facility. Journal of Animal Science, v. 86, p.2190-2207, 2008.

MANNO, M.C.; OLIVEIRA, R.F.M.; DONZELE, J.L. et al. Efeito da temperatura ambiente sobre o desempenho de suínos dos 15 aos $30 \mathrm{~kg}$. Revista Brasileira de Zootecnia, v.34, p.1963-1970, 2005.

NUNES, C.G.V.; OLIVEIRA, R.F.M.; DONZELE, J.L. et al. Níveis de lisina digestível para leitões dos 6 aos $15 \mathrm{~kg}$. Revista Brasileira de Zootecnia, v.37, p.84-88, 2008.

OLIVEIRA, R.F.M.; DONZELE, J.L. Effect of environmental temperature on performance ando $\mathrm{n}$ physiological and hormonal parameters of gilts fed different levels of digestible energy. Animal Feed Science and Technology, v.81, p.319-331, 1999

ORLANDO, U.A.D.; OLIVEIRA, R.F.M.; DONZELE, J.L. et al. Nível de proteína bruta para leitoas dos 30 aos $60 \mathrm{~kg}$ mantidas em ambiente de alta temperatura $\left(31^{\circ} \mathrm{C}\right)$. Revista Brasileira de Zootecnia, v.30, p.1536-1543, 2001.

PATIENCE, J.F.; UMBOH, J.F.; CHAPLIN, R.K. et al. Nutritional and physiological responses of growing pigs rxposed to a diurnal pattern of heat stress. Livestock Production Science, v.96, p.205-214, 2005.

PERDOMO, C.C. Conforto ambiental e produtividade de suínos. In: SIMPÓSIO LATINO-AMERICANO DE NUTRIÇÃO DE SUÍNOS, 1994, São Paulo. Anais... São Paulo: CBNA, 1994. p.19-26.

ROSTAGNO, H.S.; ALBINO, L.F.T.; DONZELE, J.L. et al. Tabelas brasileiras para aves e suínos: composição de alimentos e exigências nutricionais. Viçosa, MG: Universidade Federal de Viçosa, 2005. 186p.

SANTOMÁ, G.; PONTES, M. Interaccion nutricion-manejo en explotacione para aves y porcino. 1. Introducción y factores ambientales. In: CURSO DE ESPECIALIZACION FEDNA, 20. 2004, Barcelona. Procedings... Barcelona, 2004. p.151-210.

SARAIVA, E.P.; OLIVEIRA, R.F.M.; DONZELE, J.L. et al. Níveis de treonina Digestivel em rações para leitoas dos 15 aos $30 \mathrm{~kg}$ mantidas em ambiente de alta temperatura. Revista Brasileira de Zootecnia, v.35, p.485-490, 2006.

SARAIVA, E.P.; OLIVEIRA, R.F.M.; DONZELE, J.L. et al. Exigências de treonina digestível para leitoas mantidas em ambiente termoneutro dos 15 aos $30 \mathrm{~kg}$. Revista Brasileira de Zootecnia, v.36, p.1861-1867, 2007.

SARAIVA, E.P.; OLIVEIRA, R.F.M.; DONZELE, J.L. et a1. Exigências de treonina digestível para leitoas mantidas em ambiente termoneutro dos 30 aos $60 \mathrm{~kg}$. Revista Brasileira de Zootecnia, v.36, p.1854-1860, 2007.

SCHINCKEL, A.P.; EINSTEIN, M.E. [2001]. Concepts of pig growth and composition. Disponível em: $<\mathrm{http}: / / \mathrm{www}$.anse.purdue.edu/ swine/porkpage/growth/pubs>. Acesso em: 22 mar. 2008.

SILVA, D.J. Análise de alimentos: métodos químicos e biológicos. Viçosa-MG: UFV, Imprensa Universitária, 1990. 166p.

TAVARES, S.L.S.; OLIVEIRA, R.F.M.; DONZELE, J.L. et al. Influência da temperatura ambiente sobre o desempenho e os parâmetros fisiológicos de suínos machos castrados dos 30 aos $60 \mathrm{~kg}$. Revista Brasileira de Zootecnia, v.29, p.199-205, 2000.

UNIVERSIDADE FEDERAL DE VIÇOSA - UFV. Sistemas de Análises Estatísticas e Genéticas - SAEG. Versão 8.0. Viçosa, MG, 2000. 142p.

WARNANTS, N.; Van OECKEL, M.J.; PAEPE, M. Response of growing pigs to different levels of ileal standardized digestible lysine using diets balanced in threonine, methionine and tryptophan. Livestock Production Science, v.82, p.201-209, 2003.

WHITTE, H.M.; RICHERT, B.T.; SCHINCKEL, B.T. et al. Effects of temperature stress on growth performance and bacon quality in grow-finish pigs housed at two densities. Journal of Animal Science, v. 86, p.1789-1798, 2008. 